\title{
Parametric evaluation of shear strength parameters on the stability of cut slope: a case study from Mahabaleshwar road section, India
}

\author{
Suman Panthee \\ Central Department of Geology, Tribhuvan University, Kirtipur, Kathmandu, Nepal \\ (Email: panthisuman@gmail.com)
}

\begin{abstract}
Stability of rock cut slopes depends upon the type of material, discontinuity attributes and geometry present in any location. Although, gravity remains the constant important factor in dictating the slope failure but other parameters like shear strength and available shear stress along the slope also decides the stability of the slopes to great extent. The strength of the material comes from the internal bonding between the mineral grains, contact between the particles and the ability of the material to respond to the stress conditions. Variation of these material attributes fluctuate the cohesion and angle of internal friction that constitutes the most important properties in defining the strength of any material. Rock resists shear stress by these two internal mechanisms. Numerical simulation by Finite Element Method technique is attempted for assessing the stability cut slope. An attempt has been made in this study to document the behavior of strength of the material in terms of stability of slopes by parametric study of cohesion and internal friction. This study carried to understand how the factor of safety changes with reference to change in cut slope height, cohesion and internal friction of the discontinuities that attributes the shear strength of discontinuities. The study is based on Finite Element Modeling (FEM). From the study it is found that factor of safety has strongly proportional relation with cohesion and internal friction but shown inversely proportional relation with height of cut slope.
\end{abstract}

Keywords: Joint shear strength, cut slope stbility, cohesion, finite element modeling (FEM)

Received: 20 December 2015

Revision received: 13 March 2016

\section{INTRODUCTION}

The study area is selected along the national highway NH72 near Mahabaleshwar, Maharastra, India. Several unstable slopes along the road section between the Poladpur and the Mahabaleshwar fail mostly in rainy season are the study sites for this study. The area comprises basaltic rock of Deccan Trap with three sets of joints. Rock slope with very thin to no soil and almost no vegetation was observed along the study area. Stability of slopes in this study is assessed by parametric study of cohesion and internal friction for the rock types of moderate strength and slightly weathered condition. Therefore, generalized values of both the parameters are assumed to depict the natural conditions for the mentioned rock types. The area receives heavy rainfall during monsoon ranging between 900-1100 mm/year. Numerical simulation of Mahabaleshwar road cut slope is analyzed in this study where frequent small scale landslides occur mainly in the rainy season. The NH72 is an important link between Poladpur to Mahabaleshwar where thousands of commuters travel every day. The blocking of roads due to failed slope causes huge distress. To tackle this problem, a numerical modeling tool, finite element modeling (FEM) approach is utilized in this study to evaluate the stability of slopes under varying conditions of the two internal properties of the material. FEM is considered for the present purpose of study because the material considered is devoid of any discontinuities and anisotropy resulting from mineral composition and stability of jointed rock mass depends upon the cohesion and internal friction of the joints of the rock mass (Panthee et al. 2016). Frequent field visits were conducted throughout the study to collect samples and to properly define the slope attributes. A set of geotechnical tests -shear box and tribometer, that including determination of cohesion and internal friction on the properly cut samples were also conducted in the laboratory to gauge into the prevailing condition of rocks. From the field JRC values were collected.

\section{METHODOLOGY}

Stability of slopes has been a great area of concern these days. From building homes in mountainous regions to road cut slopes along highways, it is a cause of concern to mankind and property (Kainthola et al. 2015). Rainfall results in the saturation of the material and disrupts its coherence. Cohesion is the measure of internal bonding of the rock material while internal friction is the result of inter-particle contact. Rock resists shear stress by two internal mechanisms, cohesion and internal friction. One of the main parameters which define the stability of slopes is shear strength of the material concerned which also depends upon the confining stresses. Cohesion and internal friction is related to shear strength of the material through Coulomb's law which states that,

\section{Where,}

$$
\tau \mathrm{f}=\mathrm{c}+\sigma \mathrm{n} \tan \varphi
$$

$\tau \mathrm{f}$ is the shear stress along the shear plane at failure, $\mathrm{c}$ is the cohesion,

$\sigma \mathrm{n}$ is the normal stress acting on the shear plane, and

$\varphi$ is the friction angle of the shear plane 
Accordingly, three types of geological material may exist. These are:

1. $\mathrm{c}=0$ (materials exhibiting no cohesion, such as dry sand)

2. $\mathrm{c}$ and $\phi$ materials (soils and rocks with both cohesion and internal friction)

3. $\phi=0$ (materials exhibiting no internal friction)

\section{Numerical Modeling}

Numerical methods such as the Finite Element Method (FEM) have now been successfully applied to slope stability analysis over the years (Singh et al. 2013a, b and 2015; Kainthola et al. 2013). It is now assumed as the best alternative to traditional limit equilibrium methods, possibly because of less number of priori assumption is required for the analysis (Verma et al. 2013). The FEM is the most widely sought numerical methods for rock mechanics problems in engineering geology because of its flexibility for treatment of material heterogeneity, complex boundary conditions, in situ stresses and gravity (Jing 2003). The material considered in the present study is anisotropic basalt, with discontinuities for the sake of making simulations easier and understanding the role of cohesion and internal friction in the stability of slopes. Slope geometry is constructed to approximate the actual slope by collecting data and samples through frequent field visits. Upon the definition and plotting of the geometry and assigning material properties obtained from tests conducted in laboratory, the geometry has to be further divided into finite elements to perform finite element calculations which are taken care by the FEM tool based on proper understanding. A general formula used to calculate FOS from the values of shear strength and shear stresses is depicted below.

$$
\text { Factor of safety }=\frac{\text { Shear Strength }}{\text { Shear Stress }}=\frac{\mathrm{cA}+\mathrm{W} \cos (\psi) \tan \varphi}{\mathrm{W} \sin (\psi)}
$$

\section{Where,}

c (MPa) is cohesion

$\varphi$, angle of internal friction

$\psi$, dip of the sliding surface

A, the area of sliding surface and

$\mathrm{W}$, the weight of the block lying above the sliding surface.

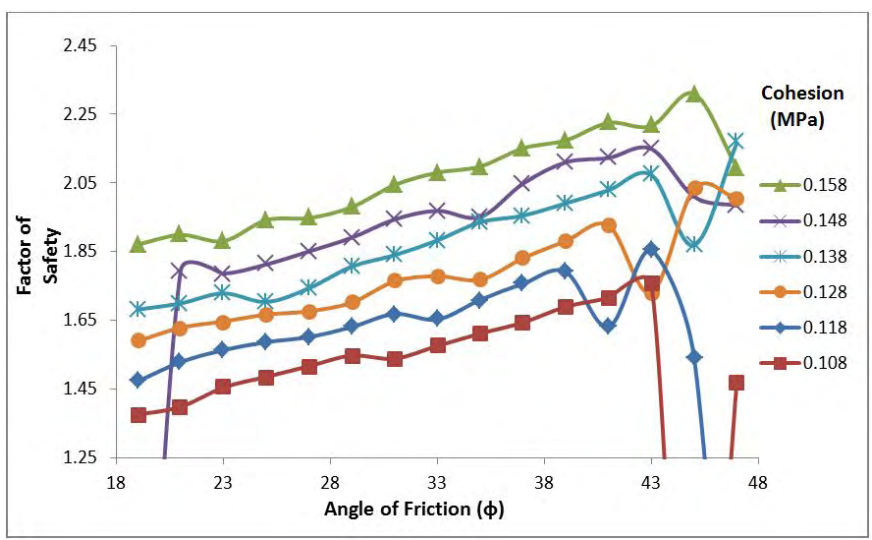

Fig. 1: Relation between FOS and Phi for varying cohesion as per gravity loading.
The strength of the rock mass is determined by the combined strength of the rock and the presence of discontinuities in it. Depending on the size of the weakness zone, the problems can be treated as a continuous or discontinuous problem. For large scales, a fault or weakness zone can be treated as a joint and can be analyzed as a discontinuity. The problem in this study is assumed to follow continuous behavior because of neglecting the discontinuities. Analysis of problems in geotechnical engineering requires the specification of a set of initial stresses. This is done by loading the rock body of its own weight caused by gravity. This represents the equilibrium state of the undisturbed rock body. There are two generally used methods in the FEM software (Plaxis). The first set uses the $\mathrm{K} 0$ procedure while the second set uses the gravity loading procedure. For the current scenario, gravity loading procedure is applied instead of $\mathrm{K} 0$ procedure because of its ability in modeling non-horizontal stress conditions. The slope has been modeled using shear strength reduction (SSR) technique which is commonly used in various rock engineering environments. The discontinuities were incorporated into the model based on field conditions. The meshing used in the model is graded 3 -node triangle, which is further refined near the slopes.

\section{Gravity loading}

The initial stresses corresponding to the initial phase are assumed to be zero. These are then set up but applying the self-weight of the material concerned in the first calculation phase. In the second phase, FOS is calculated by incorporating the results obtained from the tests. Stability of slopes is then tested for a range of values of cohesion and internal friction. A correlation between slope height, internal friction and cohesion is made in the study to better understand the role of these parameters on the stability of slopes.

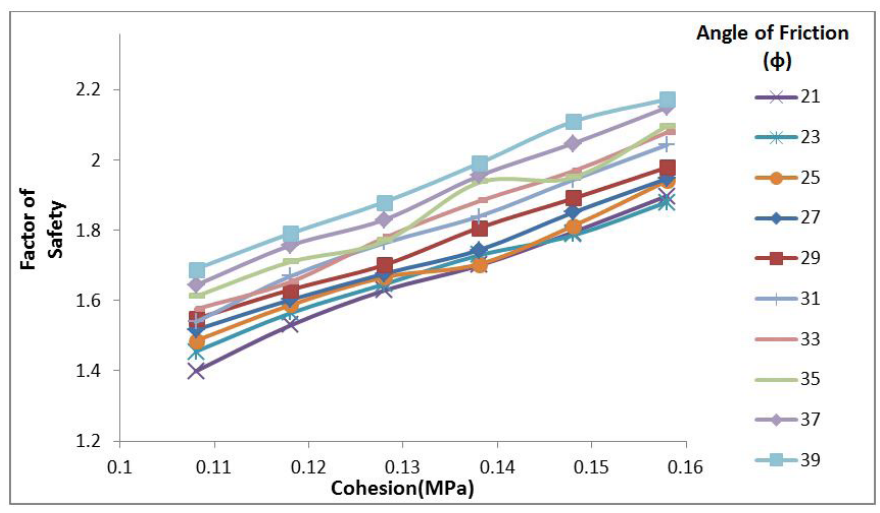

Fig. 2: Relation between FOS and cohesion for varying Phi as per gravity loading

Internal friction is caused by contact between particles and is defined by the internal friction angle, $\varphi$. By better understanding the rock's internal properties, one can aim to reduce the stability problems that may occur. Cohesion and angle of internal friction are directly proportional to the factor of safety while the bench height is inversely proportional. It can be seen from the two sets of plots that factor of safety increases with an increase in angle of internal friction (Fig. 1) and cohesion (Fig. 2). 
Parametric evaluation of shear strength parameters on the stability of cut slope in the Mahabaleshwar

Table 1: Correlation between shear strength parameters and slope height (Cohesion=0.118 MPa)

\begin{tabular}{|l|l|l|l|l|}
\hline Slope Height (m)/Angle of internal friction & 19 & 21 & 23 & 25 \\
\hline 18.974 & 1.473 & 1.529 & 1.564 & 1.587 \\
\hline 19.974 & 1.322 & 1.345 & 1.381 & 1.427 \\
\hline 20.974 & 1.236 & 1.264 & 1.296 & 1.323 \\
\hline 21.974 & 1.162 & 1.186 & 1.211 & 1.237 \\
\hline 22.974 & 1.074 & 1.108 & 1.141 & 1.171 \\
\hline 23.974 & 1.029 & 1.052 & 1.066 & 1.11 \\
\hline
\end{tabular}

Further correlation shows that the factor of safety increases with increase in the angle of internal friction for a constant slope height (Fig. 3) and decreases with increase in slope height for a particular angle of internal friction (Fig. 4). Singh et al. (2013c) have also conducted similar study and suggested that shear strength parameters along with height of the slope are very important parameters for overall stability of slopes and that as the height increases and shear strength parameters decrease, global safety factor also decreases. Results from this study have also been compiled in tabular format for these data sets (Table 1).

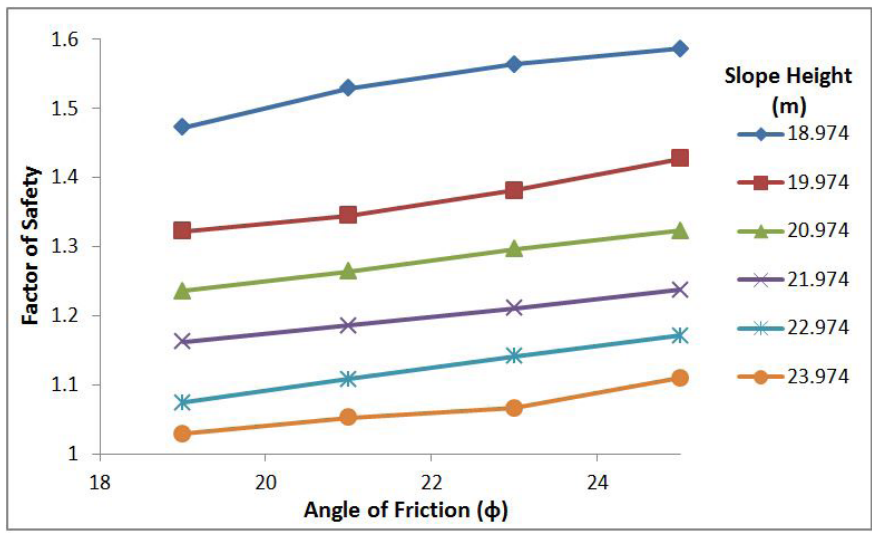

Fig. 3: Relation between FOS and Phi for a constant slope height.

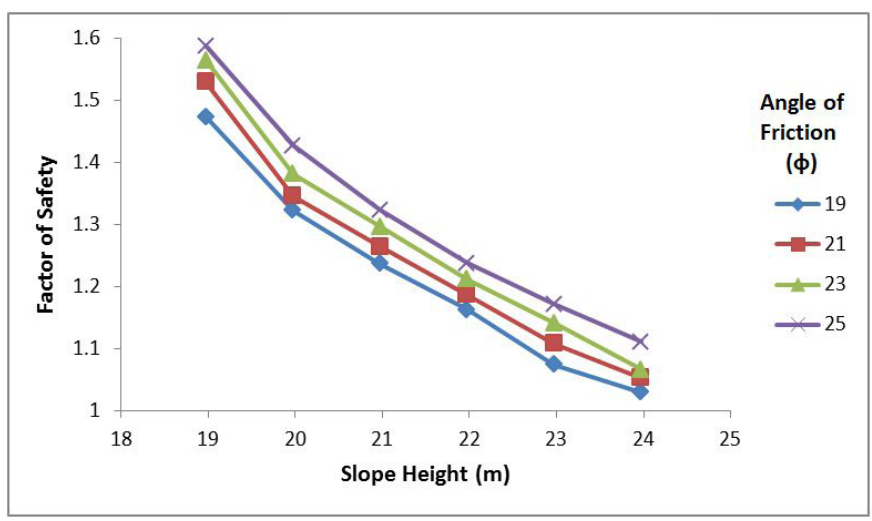

Fig. 4: Relation between FOS and slope height a constant internal friction.

Kainthola et al. (2015) and Singh et al. (2013a, b and c) have carried out stability of cut slope in almost similar terrain and similar rock type. Their research also indicated the cohesion and internal friction are key parameters for stability. The output of present research is also shown the similar result. Singh et al. (2015) have studied failed slope in similar condition and point out the shear strength reduction up to the failure level was the finding of the failure cause. The present study also shown that safety factor decreases with decreasing the shear strength value. Similarly, Panthee et al. (2016) were study of stability of tunnel failure with reference to joint persistency cohesion and internal friction for different rock types and found persistency cohesion and internal friction of joints are highly influencing parameters in stability which supports the present study.

\section{CONCLUSIONS}

Stability pattern of the road cut slope along NH 72 is analyzed in this study. Due to heavy rainfall, the two main internal strength parameters of the materials viz cohesion and internal friction loses its coherence and decreases the strength of the material. So, to model this complex behavior in anisotropic condition parametric study was conducted for different possible ranges of these parameters. Numerical tool like FEM approach was adopted in this study to reach to a reasonable correlation between shear strength parameters and slope height. The results clearly illustrate the factor of safety increases with an increase in both shear strength parameters as expected. On increasing the slope height, while keeping the angle of internal friction and cohesion constant, we see a decrease in the factor of safety with height rendering the slope unstable.

From the study it is found that factor of safety has strongly relation with cohesion and internal friction of the discontinuity and factor of safety decreases as height of cut slope increases. The rain, during the season, decreases the cohesion and internal friction of the discontinuities and failure were resulted.

\section{REFERENCES}

Jing, L., 2003, A review of techniques, advances and outstanding issues in numerical modeling for rock mechanics and rock engineering, Int. Jour. Rock Mech. Mining Sci., v. 40, pp. 283-353.

Kainthola A., Singh, P. K., Wasnik, A. B., Sazid, M., and Singh, T. N., 2012, Finite Element Analysis of Road Cut Slopes using Hoek and Brown Failure Criterion. Int. Jour. Earth Sci. Eng. v. 5(5), pp. 1100-1109.

Kainthola, A., Verma, D., Thareja, R., and Singh, T. N., 2013, A review on numerical slope stability analysis. Int. Jour. Sci., Eng. Tech. Res. v. 2(6), pp. 1315-1320.

Kainthola, A. Singh, P. K., and Singh, and T. N., 2015, Stability inves- 


\section{Suman Panthee}

tigation of road cut slope in basaltic rockmass, Mahabaleshwar, India. Geosci. Frontiers, v. 6(6), pp. 837-45.

Panthee, S., Singh P. K., Kainthola, A., and Singh, T. N., 2016, Control of rock joint parameters on deformation of tunnel opening. Jour. Rock Mech. Geotech. Eng, v. 8, pp. 489-498 Doi: 10.1016/j.jrmge.2016.03.003.

Singh, P., K., Kainthola, A., Prasad S., and Singh, T. N., 2015, Protection Measures on the Failed Cut-slope along the Free Expressway, Chembur, Mumbai, India. Jour. Geol. Soc. India, v. 86(6), pp. 687-695.

Singh, T. N., Ahmad M., Kainthola, A., Singh, R., and Kumar, S., 2013a, A stability assessment of a hill slope - an analytical and numerical approach. Int. Jour. Earth Sci Eng., v. 6(1), pp. 39-49.

Singh, P. K., Wasnik, A. B., Kainthola A, Sazid, M., and Singh T. N., 2013b, The stability of road cut cliff face along SH-121: a case study. Natural Hazards, v. 68(2), pp. 497-507.

Singh, P. K., Kainthola, A., Singh, R., Gupte, S., Maji, V., and Singh, T. N., 2013c, Estimation of critical parameters for slope instability in an In-pit mine dump. SGAT Bulletin, v. 14(1), pp. 34-44.

Verma, D., Kainthola, A., Thareja, R. and Singh, T. N., 2013, Stability analysis of an open cut slope in Wardha valley coal field. Jour. Geol. Soc. India, v. 81 (6), pp. 804-812. 